\title{
Farklı Yüzey Aktif Maddelerin Soya Bitki Kuru Ağırlığına Etkileri
}

\author{
Illknur YURDAKUL I* $\quad$ Kadriye KALINBACAK² İbrahim GEDIKOĞLU³ \\ 11 Toprak Gübre ve Su Kaynakları Merkez Araștırma Enstitüsü Müdürlüğü, Ankara \\ ${ }^{2}$ T.C. Gıda Tarım ve Hayvancılık Bakanlığı, Tarımsal Araștırmalar ve Politikalar Genel Müdürlüğü, Ankara, \\ ${ }^{3}$ T.C. Gençlik ve Spor Bakanlığı, İı Müdürlüğü, Ankara,
}

\footnotetext{
*Sorumlu yazar e-posta (Corresponding author e-mail): ilknur_yurdakul@yahoo.com Geliș tarihi (Received) : 9.10.2014

Kabul tarihi (Accepted) : 13.04.2015
}

\section{Öz}

Illk yoğun kullanımının salgın hastalıkların önlenmesinde ve temizlik ișlerinde 1960'lı yıllarda olduğu deterjanların, su ve toprakta bozunmadan kalması ve bu sularla yetiștirilen bitkileri etkilemesi, akarsulara, göllere ve denizlere ulașması canlıları ve insan sağlığını tehdit etmektedir. Bu durum doğanın kirlenmesinde önemli rol oynayan bu maddeler konusunda önlem alma zorunluluğunu ortaya çıkarmaktadır. Çalıșma anyonik, katyonik ve iyonik olmayan Yüzey Aktif Maddelerin (YAM), soyanın (Glycine max L.) gelișimine etkilerini belirlemek amacıyla gerçekleștirilmiștir. Deneme; tuzsuz, hafif alkalin reaksiyonlu, organik madde ve fosforu düșük, kireç ve potasyum kapsamı fazla, killi tınlı bünyeli toprağa, $180 \mathrm{mg} \mathrm{N} \mathrm{kg}^{-1}$ (\% 26'lık amonyum nitrat) ve $100 \mathrm{mg} \mathrm{P} \mathrm{kg}^{-1}$ (\% 42-44'lik Triple Süperfosfat) ilavesiyle tesadüf parselleri deneme deseninde 3 tekrarlamalı olarak serada kurulmuștur. Soya ekiminden sonra, YAM'ler 0, 180, 360, 540 ve $720 \mathrm{mg} \mathrm{kg}^{-1}$ seviyelerinde saksılara uygulanmıștır. Soya hasatı ekilișten 50 gün sonra yapılımıștır. Anyonik YAM ve iyonik olmayan YAM uygulaması soya kuru ağırlıklarında ( $p<0.01$ ) azalma meydana getirmiș, katyonik YAM ise bir fark olușturmamıștır. Bitki kuru ağırlığının anyonik ve iyonik olmayan YAM'ler tarafından kısıtlandığı ve azaldığı, soyanın anyonik ve iyonik olmayan YAM bileșiklerine hassasiyet gösterdiği belirlenmiștir. Çalıșma sonuçlarına göre; bu bileșiklerin muhtemelen kök bölgesinde bitki gelișimini olumsuz etkilediği söylenebilir.

Anahtar Kelimeler: Anyonik, iyonik olmayan yüzey aktif maddeler, katyonik, sera soya (Glycine max L.)

\section{The Effects of Different Surfactants on Soybean Plant Dry Weight}

\begin{abstract}
The first using of detergents to intercept epidemic diseases and clean materials with a majority is in 1960s. Detergents remain in water and earth without decomposing. These contaminated waters affect growing plants badly and threaten the livings in rivers, lakes and seas and the health of people. These substances play an important role in natural and environmental pollution. The compulsion of taking precautions arises. This study has been realized with the purpose of being determined the effects of anionic, cationic and nonionic surfactants to the development of soybean. The soil of greenhouse, used for the study is within the scope of much lime and potassium, light alkali reactive, little organic material and phosphorus, clay and without salt. The research was conducted as randomized split parcels with 3 repetitives in greenhouse. Testing was designed with the addition of $180 \mathrm{mg} \mathrm{N} \mathrm{kg}^{-1}$ (26\% Ammonium Nitrate) and $100 \mathrm{mg} \mathrm{P} \mathrm{kg}^{-1}$ (42-44\% triple super phosphate). After soybean sowing, surfactants were applied to the pots with varying degrees $0,180,360,540$ and $720 \mathrm{mg} \mathrm{kg}^{-1}$. Soybean was harvested 50 days later from sowing. Anionic and nonionic surfactants caused a decrease dry weight of soybean shoots $(p<0.01)$. Cationic surfactant did not cause to decrease dry weight of the plant significantly. Dry weight of soybean is limited and reduced the by anionic and nonionic surfactants. Soybean plant was determined to
\end{abstract}


be sensitive anionic and nonionic compounds. According to the results of this study these surfactants negatively affect the growth of plant especially in root area.

Key Words: Anionic, nonionic surfactants, cationic, greenhouse, soybean (Glycine max L.)

\section{Giriș}

Dünya'da 1800 yıllarında makineleșmenin etkisi ile doğanın tahribi hızlanmıș ve ekolojik denge bozulmaya bașlamıștır. Çevre kirliliğinde ve doğal dengenin bozulmasında insanoğlunun doğayı egemenliği altına alma düșüncesi yatmaktadır. Antropojenik faaliyetler neticesinde olușan atıklar, hızlı gelișen sanayi atıkları çevre kirliliğinin temel kaynaklarını olușturmaktadır. Kirlilik kaynakları içerisinde son 30 yılda deterjan yüzey aktif maddelerinden (YAM) çokça bahsedilmektedir. Son yıllarda yapılan çalıșmalarla çevresel kirliliğin nedeni olan anyonik YAM'lerin SIVI, yarı SIVI ve katı ortamlardan uzaklaștırılması ile ilgili metotlar çalıșılmaktadır. Çünkü bunlar yașayan organizma için çevresel bir tehdit olmakla birlikte, diğer kirlilik olușturucu organik ve inorganik etmenlerin parçalanarak çevreye yayılmasına neden olmaktadırlar (Cserhati vd., 2002). Nem tutucu ajanlar ve YAM'ler herbisit ve pestisitlerin terkibinde, Sıvı gübrelerin etkinliğinin arttırımasında kullanılmaktadırlar (McFarland vd., 2005). Düșük konsantrasyonlar sıvıların yüzey tansiyonunu düșürmek suretiyle sudan daha fazla faydalanılmasını sağlamak, çözünürlük ve çift fazlı sistemlerde stabilite etkisi için de kullanılmaktadır (Parr ve Norman, 2014). YAM'ler çevresel kirliliği yaratan bileșikler (Matthew ve Jones, 2000) olarak doğada bulunmaktadırlar. YAM'ler ticari gübrelerde (Spurrier ve Jackobs, 1955), bakteri uzaklaștırmada (Salager, 2002) ve kișisel bakım ürünlerinde de (Feigenbaum ve Bischoff, 2009) kullanılmaktadır. Sentetik deterjanlardaki YAM'ler genellikle kutupsal nitelik tașımayan bir hidrokarbon kısım ile kutupsal nitelikte anyonik, katyonik veya iyonik olmayan fonksiyonel bir gruptan olușmaktadır.

Su Kirliliği Kontrolü Yönetmeliğinde (31 1 12.2004 tarih/25678 sayllı) evsel ve endüstriyel atık sular için alıcı ortama deșarj standartlarında arıtma tesisi yapma ve limit değerlere uyma zorunluluğu getirilmiștir. Ancak yine de su kaynaklarına deterjanlarla birlikte YAM'ler ulașmaktadır. Tarımsal faaliyetlerle de kullanılabilen bu su kaynakları dolayısı ile bitkilerin bu maddelerden etkilenmesi söz konusu olmaktadır. Gübre dolgu maddelerinde (nemlendirici ve dağıtıcı amacı için) kullanılan
YAM'lerin herbisitler aracılığı ile de topraklara giriși söz konusu olmaktadır. Pestisitlere ilave edilmesi gereken adjuvantların uygun olmayanları veya yüksek dozlarda kullanılmaları da bitkilerin zarar görmesine neden olmaktadır (Yang, 2008; Czarnota ve Thomas, 2013). Arpada $300 \mathrm{mg} \mathrm{kg}^{-1}$ iyonik olmayan YAM (Baird ve Zublena, 1997). buğday \% 0,1 düzeyinde anyonik YAM (Srivastava vd., 2012; Yılmaz ve Dane, 2013) bitkinin veriminde azalmaya neden olmuștur. Kil fraksiyonu ve organik madde tarafindan adsorplanan YAM su geçirgenliğinin azalmasına neden olarak (Renshaw vd., 1997) verimde düșmelere neden olmaktadır. Yabancı ot kontrolünde de kullanılan YAM'lerin bitkilere etkilerinin kontrolünde YAM'siz uygulamalarda patates ve mısırın veriminin daha iyi olduğu (Shimi, 2000; Idziak ve Woznica, 2013) bildirilmektedir.

Birleșmiș Milletler Biyolojik Çeșitlilik Sözleșmesinde de belirtildiği gibi ekolojik yaklașım "arazi, su ve canlı kaynakların entegre yönetimi için koruma ve sürdürülebilir kullanımı hakkaniyetli bir șekilde teșvik eden bir strateji" (BMBÇS, 1992), olarak doğal dengeyi koruyan kirliliği ve doğaya etkiyi azaltan yaklașım tüm insanlığın asli görevidir. Ekolojik yönetim için șu andaki kirletici unsurların etkilerinin ve zararlarının da tespit edilmiș olması gereklidir. Bu amaçla çalıșmada ekolojik dengeyi bozan kirlilik etmenlerinden biri olan YAM'lerden anyonik, katyonik ve iyonik olmayan özelliklere sahip üç madde sera șartlarında yetiștirilen soya bitkisine uygulanarak, bu maddelerin bitki kuru ağırlığı üzerine etkileri incelenmiștir.

\section{MATERYAL ve METOT}

Çalıșmada test bitkisi olarak soya (Glycine max L.) A 3127 çeșidi ve yüzey aktif madde olarak anyonik YAM Linear Alkyl Benzene Sulfonic Acid (LABSA), katyonik YAM Quaternary Ammonium Compounds (Dodigen 226) ve iyonik olmayan YAM olarak Alkyl Polyglycol Ether (Dehydol LS7F) kullanılmıstır. LABSA, hidrofilik ve hidrofobik grup içeren düz zincirli, biyolojik olarak parçalanabilmektedir (Anonymous 1, 2014). Dodigen 226; plastik çeșitleri içerisinde çok az zararlı etkiye sahip, bakteri, virüs ve fungiye karșı 
antimikrobiyal özellikler barındırmaktadır (Cross ve Singer, 1994). Dehydol LS7F; asidik ve alkalin ortamda kararlı olan, sinerjistik etkilerinden dolayı anyonik ve katyoniklerle birlikte kullanılan (Anonymous 2, 2014) maddelerdir.

Çalıșmada kullanılan toprak, tuzsuz $(\% 0,08)$, hafif alkalin reaksiyonda $(\mathrm{pH} 7,87)$, organik madde $(\% 2,1)$ ve fosforu $\left(2,7 \mathrm{P}_{2} \mathrm{O}_{5} \mathrm{~kg}\right.$ da $\left.{ }^{-1}\right)$ düșük, kireç $(\%$ $20,3)$ ve potasyum kapsamı $\left(84,6 \mathrm{~K}_{2} \mathrm{O} \mathrm{kg} \mathrm{da-1}\right)$ fazla olan killi tınlı bünyelidir (Çizelge 1). Toprak örnekleri, 0-20 cm derinlikten özel yapılmıș pirinç alașımlı bir kürek ile alınmıșlar ve bez torbalara konularak seraya nakledilmișlerdir (Jackson, 1962). Kuruyan topraklar $4 \mathrm{~mm}$ ve $2 \mathrm{~mm}$ 'lik eleklerden geçirilerek serada kullanıma ve laboratuvar analizlerine hazırlanmıșlardır. Toprak tepkimesi; saf suyla hazırlanan doygun toprakta pH-metre kullanılarak, toplam tuz; suyla doygun toprağın elektriksel iletkenliğinin iletkenlik aletiyle ölçülmesiyle, yarayıșlı potasyum; ekstrakt çözeltisi olarak $1 \mathrm{~N} \mathrm{NH}_{4} \mathrm{OAc}(\mathrm{pH}$ $7,0)$ kullanmak ve ekstrakta geçen potasyumu alev fotometresi ile ölçerek tayin edilmiștir (Richards, 1954). Tarla kapasitesi, toprakların 1/3 atmosfer basınç altında tutabildikleri su miktarı olarak, solma noktası 15 atmosfer basınçtaki su miktarı olarak (U.S. Salinity Lab. Staff 1954) bulunmuștur. Bünye (kum, silt ve kil) hidrometre yöntemine göre (Bouyoucus, 1951), kireç, Scheibler kalsimetresi (Martin ve Reeve, 1955) kullanılarak, organik madde, modifiye Walkley-Black (Walkley ve Black, 1934) yöntemine göre tayin edilmiștir. Yarayıșı fosfor, ekstrakt çözeltisi 0,5 $\mathrm{M} \mathrm{NaHCO}_{3}(\mathrm{pH} 8,5)$ olan Olsen vd., (1954) tarafından geliștirilen yöntemle saptanmıștır.

\section{Deneme Deseni}

Deneme tuzsuz, hafif alkalin reaksiyonda, organik madde ve fosforu düșük, kireç ve potasyum kapsamı fazla olan killi tınlı bünyeli toprak ile tesadüf parselleri deneme desenine göre 3 tekrarlamalı olarak sera koșullarında kurulmuștur. Denemedeki saksılara $2500 \mathrm{~g}$ toprak konulmuș ve her saksıya 6 adet tohum ekilmiștir. Tohumlar çimlendikten sonra her bir saksıda 3 adet tohum kalacak șekilde seyreltilmiștir. YAM uygulamaları 0, 180, 360, 540 ve $720 \mathrm{mg} \mathrm{kg}^{-1}$ seviyelerinde bir defada soya ekiminden hemen sonra yapılmıștır. Topraklara azotlu gübre olarak amonyum nitrat (\% $26 \quad \mathrm{~N})$ kaynaklı $180 \mathrm{mg} \mathrm{N} \mathrm{kg}^{-1}$ olacak șekilde azot ve fosforlu gübre olarak triple süperfosfat (\% 42-44 $\mathrm{P}_{2} \mathrm{O}_{5}$ ) kaynaklı $100 \mathrm{mg} \mathrm{P} \mathrm{kg}^{-1}$ olacak șekilde fosforlu gübre uygulanmıștır. Bitkilerin gelișimi takip edilmiș ve ekilișten 50 gün sonra bitkiler toprak hizasından paslanmaz çelikten yapıImıș makasla hasat edilerek, laboratuvarda yıkanmıș, $65^{\circ} \mathrm{C}$ 'de hava sirkülasyonlu fırında kurutulmuș ve bitki kuru ağırlıkları belirlenmiștir.

\section{BULGULAR VE TARTISTMA}

Killi tınlı toprakta yetiștirilen soyaya artan düzeylerde uygulanan anyonik YAM bitki kuru ağırlığında azalmaya neden olmuștur. Kontrol konusunda ortalama bitki kuru ağırlığı 4,00 g saksı ${ }^{-1}$ elde edilirken, uygulama dozu arttıkça bitki kuru ağırlık miktarı azalmıștır. En yüksek dozda (720 mg $\mathrm{kg}^{-1}$ ) bitki kuru ağırlığı ortalama 1,34 $g$ saksI $^{-1}$ seviyesine düșmüștür. Katyonik YAM uygulamalarında ise önce artıș göstermiș daha sonra düșmeye ve artmaya bașlayarak dalgalanma olușmuștur. İyonik olmayan YAM uygulamalarında bitki kuru ağırlık miktarlarında ilk dozdan bașlayarak değerlerde azalma olmuștur. Kontrol konusunda 4,40 $\mathrm{g} \mathrm{saksı}^{-1}$ olan bitki kuru ağırlık değeri en yüksek uygulamada $3,13 \mathrm{~g}$ saksı $^{-1}$ seviyesine kadar düșmüștür (Çizelge 2). Toprağa artan düzeylerde uygulanan anyonik ve iyonik olmayan YAM soya bitkisinin kuru ağırlıklarında önemli düzeyde azalma meydana getirmiștir. Uygulamalar ve kuru ağırlık arasındaki ilișkilerin denklemi anyonik ve iyonik olmayan sırası ile $y=-0,0036 x+4,274, R^{2}=\% 78$, $y=-0,0018 x+4,4533, \quad R^{2}=\% 46$ olarak bulunmuștur. Uygulanan anyonik ve iyonik olmayan YAM dozları arttıkça bitki kuru ağırlıkları azalmıș ve korelasyon katsayısı soyada anyonik ve iyonik olmayan YAM sırası ile $r=-0,881, p<0,01$, $r=-0,676, p<0,01$ olmuștur. Katyonik YAM uygulamalarının soyanın kuru ağırlık değerlerindeki etkisi önemli bulunmamıștır ( Șekil 2, Çizelge 2).

Çizelge 1. Toprağın bazı fiziksel ve kimyasal özellikleri

Table 1. Some physical and chemical properties of used soil

\begin{tabular}{cccccccccccc}
\hline Mevki & $\begin{array}{c}\text { Kum } \\
(\%)\end{array}$ & $\begin{array}{c}\text { Silt } \\
(\%)\end{array}$ & $\begin{array}{c}\text { Kil } \\
(\%)\end{array}$ & $\begin{array}{c}\text { Tarla } \\
\text { Kapasitesi } \\
(\%)\end{array}$ & $\begin{array}{c}\text { Erime } \\
\text { Noktası } \\
(\%)\end{array}$ & $\begin{array}{c}\text { Toplam } \\
\text { Tuz } \\
(\%)\end{array}$ & $\begin{array}{c}\text { Kireç } \\
\mathrm{CaCO}_{3} \\
(\%)\end{array}$ & $\begin{array}{c}\text { Org. } \\
\text { Mad. } \\
(\%)\end{array}$ & $\begin{array}{c}\mathrm{PH}_{2} \mathrm{O}_{5} \\
(\mathrm{~kg}\end{array}$ & $\begin{array}{c}\mathrm{K}_{2} \mathrm{O} \\
\left(\mathrm{kg}^{-1}\right)\end{array}$ & $\begin{array}{c}\left(\mathrm{kg}^{-1}\right) \\
\mathrm{da}^{-1}\end{array}$ \\
\hline Incek & 33.3 & 29.9 & 36.8 & 32.7 & 16.9 & 0.08 & 20.3 & 2.1 & 7.8 & 2.7 & 84.6 \\
\hline
\end{tabular}




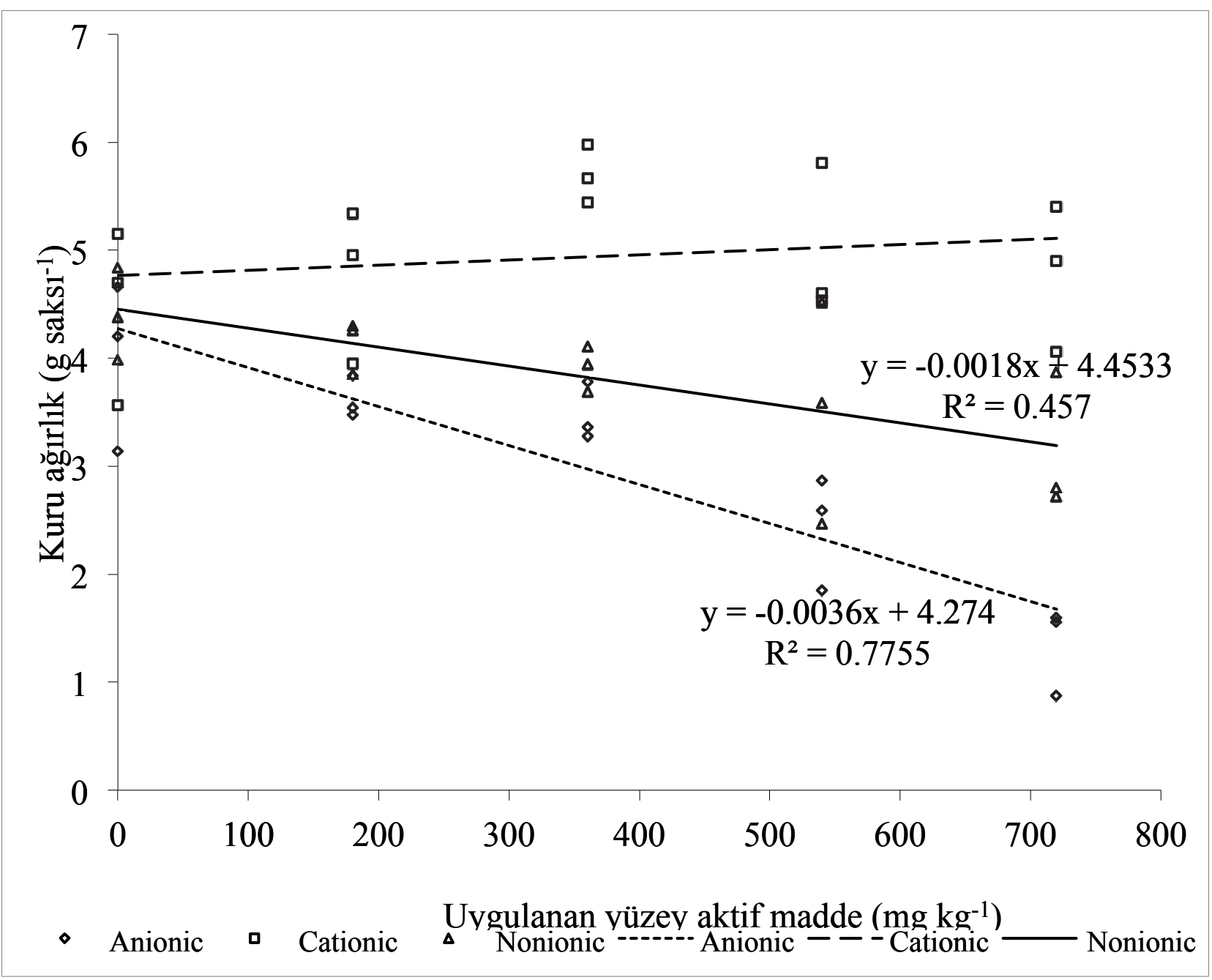

Șekil 1. Artan düzeylerde yüzey aktif madde ile bitki kuru ağırlığı arasındaki ilișki.

Figure 1. The relation between dry weight of soybean and increasing levels of surfactants

Gerçekleștirilen çalıșma sonucunda soyanın bitki kuru ağırlığının anyonik ve iyonik olmayan YAM'ler tarafından kısıtlandığı ve azaldığı, soyanın LABSA ve Dehydol LS7F bileșiklerine hassasiyet gösterdiği tespit edilmiștir. Ayrıca bu bileșiklerin köklerin yapısını bozmak sureti ile bitki gelișimini olumsuz etkilediği görülmüștür.

Geçmiș çalıșmalarda da sprey pestisitlerde katkı maddesi olan YAM'lerin besin solüsyonundaki sorgum köklerine uygulanması ile uygulamadan birkaç saat sonra köklerin membran bütünlüğünün kaybı nedeni ile iyonların ve amino asitlerin köklerden solüsyona hareket ettiği, 2-3 gün sonra bitkilerin solduğu ve yüksek YAM uygulamalarında bitkilerin öldüğü belirtilerek, İsrail'de sulama suyu olarak kullanılan kanalizasyon çıktılarına karıșan deterjanların da aynı etkiden dolayı önemli olduğu (Horowitz ve Givelberg, 1979), katyonik YAM'lerin bitkilere toksik olduğu için herbisitlerde kullanılmadığı, anyonik ve iyonik olmayan YAM'lerin bitki ve hayvanlara düșük zararlı olması nedeniyle herbisitlerde kullanıldığı (Jordan vd., 2011), kullanılan dozun çok önemli olduğu, pestisitlere ilave edilmesi gereken adjuvantların uygun olmayanları veya yüksek dozlarda kullanılmaları da bitkilerin zarar görmesine neden olduğu (Czarnota ve Thomas, 2013) açıklanmıștır.

Sera koșullarında iyonik olmayan YAM'nin yulaf, yonca ve bezelyeye $1000 \mathrm{mg} \mathrm{kg}^{-1}$ düzeyinde uygulanmasının bitkilerin gelișiminde gerilemeye neden olduğu (Luzzatti, 1981), anyonik YAM'lerin hidrofonik sistemde bitki gelișimini etkilediği (Baird ve Zublena, 1997), kökleri incelttiği, cuticleyi kalınlaștırdığı, paFrenkima hücrelerini ve hücre duvarlarını çatlattığı, endodermisi kalınlaștırdığı (Srivastava vd., 2012; Yılmaz ve Dane, 2013) bildirilmektedir. 
Çizelge 2. Artan düzeyde yüzey aktif madde uygulanan soya kuru ağırlıkları (g saksı ${ }^{-1}$ )

Table 2. The increasing levels of some surfactants application on soybean dry weight (g pot $\left.{ }^{1}\right)$

\begin{tabular}{|c|c|c|c|c|c|c|c|c|c|c|c|c|}
\hline \multirow{2}{*}{$\begin{array}{c}\text { Düzey } \\
\text { (mg } \\
\mathrm{kg}^{-1} \text { ) }\end{array}$} & \multicolumn{4}{|c|}{ Anyonik } & \multicolumn{4}{|c|}{ Katyonik } & \multicolumn{4}{|c|}{ İyonik Olmayan } \\
\hline & 1 & 2 & 3 & Ort. & 1 & 2 & 3 & Ort. & 1 & 2 & 3 & Ort. \\
\hline 0 & 4.20 & 3.14 & 4.66 & 4.00 & 5.15 & 4.70 & 3.57 & 4.47 & 4.38 & 4.84 & 3.99 & 4.40 \\
\hline 180 & 3.54 & 3.48 & 3.84 & 3.62 & 5.34 & 4.96 & 3.95 & 4.75 & 4.26 & 4.30 & 3.85 & 4.13 \\
\hline 360 & 3.78 & 3.36 & 3.28 & 3.47 & 5.98 & 5.44 & 5.67 & 5.70 & 3.69 & 3.94 & 4.11 & 3.91 \\
\hline 540 & 2.87 & 2.59 & 1.85 & 2.44 & 5.81 & 4.60 & 4.54 & 4.98 & 4.52 & 2.47 & 3.59 & 3.53 \\
\hline 720 & 0.87 & 1.60 & 1.56 & 1.34 & 4.90 & 5.40 & 4.06 & 4.79 & 2.72 & 2.80 & 3.87 & 3.13 \\
\hline
\end{tabular}

\section{SONUÇ}

Bu çalıșmada anyonik ve iyonik olmayan YAM'nin soyanın gelișimini olumsuz etkilediği saptanmıștır. Bu zararlı etkinin kök bölgesindeki YAM'lerin olumsuz etkilerinden kaynaklanabileceği ve bitkinin sağlıklı beslenmesinin engellenmiș olabileceğini düșündürebilmektedir.

Çalıșma sonuçları pestisitlerde kullanılan YAM'lerin çoğunluğunu olușturan anyonik ve iyonik olmayan YAM'lerin uygulama dozlarının ne denli önemli olduğunu da ortaya koymaktadır. Katyonik YAM uygulamalarının soyada anlamlı bir değișime neden olmadığı görülmüștür. Ekolojik dengeyi bozan faaliyetlerin kontrolü ve entegre yönetim çalıșmalarının gerekliliği yadsınamaz bir gerçektir. Koruma tedbirlerini aktifleștirmek kirlenmiș doğayı iyileștirmekten daha ucuz, daha kısa ve daha sağlıklıdır. Kirlilik kaynağı materyallerin yönetimi çok ciddi araștırma gerektiren, artılarının ve eksilerinin çok iyi değerlendirilmesi gereken konulardır.

\section{KAYNAKLAR}

Anonymous 1 (2014). Linear alkybenzene sulfonic acid. Available: http://mww.chemicalland21.com/specialtychem/perchem/LAS.htm.

Anonymous 2 (2014). Nonionic surfactants. Alkyl polyglycol ethers. Available:http://wmw.elementisspecialties.c om/esweb/esweb.nsf/pages/surfactants-nonionicsurfactants.

Baird JV, Zublena JP (1997). Using wetting agents (nonionic surfactants) on soil. North Carolina Cooperative Extension Service. AG-39-25. May 1993. (TW/K/MOC). Available:http://mww.soil.ncsu.edu/publications/Soilfacts/AG439-25/\#Deciding_When_to_Use_a_Wetting_Agent.
BMBCS. Birleșmiș Milletler Biyolojik Ceșitlilik Sözleșmesi. 1992. Kanun No: 4177. Kanun Tarihi: 28/08/1996. Resmi Gazete Tarih: 03/09/1996. Sayı: 22746. Esas No:1/289.

Bouyoucus GJ (1951). A recalibration of the hydrometer method for making mechanical analyses of soils. Agronomy Journal. 43:434-438.

Cross J, Singer EJ (1994). Cationic Surfactants: Analytical and Biological Evaluation. ISBN 0-8247-9177-0 (acid-free). Surfactants science series 53. 32. Copyright by Marcel Dekker. Inc. 270 madison Avenue. New York, 10016. USA

Cserhati TE, Forgacs E, Oros G (2002). Biological activity and environmental impact of anionic surfactants. Environ Int. 28(5):337-48.

Czarnota M, Thomas PA (2013). Using surfactants, wetting agents and adjuvants in the greenhouse. B1319. Available: http://mww.caes.uga.edu/publications/pubDetail.cfm?pk_id= 7678.

Feigenbaum H, Bischoff D (2009). The use of cationizing reagents in the preparation of conditioning polymers for hair and skin care. SKW OUAB Chemicals, Incorporated Park 80 West, Plaza 2, Suite 330 Saddle Brook, New Jersey 07663. Available:http://mmw.quab.com/files/Personal_Care_Article.pdf,

Horowitz M, Givelberg A (1979). Toxic effects of surfactants applied to plant roots. Pest Management Science. 10(6):547-557.

Idziak R, Woznica Z (2013). Effect of nitrogen fertilizers and oil adjuvants on nicosulfuron efficacy. Turkish Journal of Field Crops. 18(2):174-178.

Jackson ML (1962). Soil Chemical Analysis. Prentice-Hall Inc. Englewood, Cliffs. NY

Jordan TB, Johnson, Nice G (2011). Adjuvants Used With Herbicides: Factors to Consider. Purdue Extension Weed Science. Available:https://ag.purdue.edu/bthy/weedscience/Do cuments/Adjuvants. 
Luzzati A (1981). The effect of detergents on some plants species. II. Laboratory and field tests on oats (Avena sativa), red clover (Trifolium pretense), alfalfa (Medicago sativa) and peas organic compounds in soils. Ann Arbor Science. Publishers Inc. The Butterworth Group. 379-388.

Martin AE, Reeve $R$ (1955). A rapid manometric method for determining soil carbonate. Soil Sci. 79:187-197.

Matthew JS, Jones MN (2000). The biodegradation of surfactants in the environment. Biochimica et Biophysica ActaBiomembranes. 1508(1-2):235-251.

McFarland ML, Stichler C, Lemon RG (2005). Nontraditional soil additives: Can they improve crop production? Forages. Texas A\&M University System AgriLife Extension College Station. TX: Texas - Agrilife - Extension - Service. Available:

http://repository.tamu.edu/bitstream/handle/1969.1/87827/ pdf_934.pdf?sequence=1.

Olsen SR, Cole V, Watanable FS, Dean LA (1954). Estimation of Available Phosphorus in Soils by Extraction with Sodium Bicarbonate. U. S. Dept. of Agr. Cir. 939. Washington. D.C.

Parr JF, Norman AG (2014). Effects of nonionic surfactants on root growth and cation uptake. Available: http://www. plantphysiol.org/content/39/3/502.full.pdf.

Renshaw CE, Zynda GD, Fountain JC (1997). Permeability reductions induced by sorption of surfactants. Water Resources Research 33:371-378.

Richards LA (1954). Diagnosis and Improvement Saline and Alkaline Soils. U. S. Dep. Agr. Handbook 60
Salager JL (2002). Surfactants - Types and Uses. Venezuela: Laboratorio FIRP Escuela de Ingenieria Quimica.

Shimi P (2000). Use of flamer as a herbicide replacement in potato fields. Turkish Journal of Field Crops. 5:41-41.

Srivastava MM, Khemani LD, Srivastava S (2012). Chemistry of Phytopotentials: Healty, Energy and Environmental Perspectives. In: Effect of Anionic and Non-ionic Surfactants in Soil-Plant System Under Pot Culture, ed. Mohammad, A. and A. Moheman, 261-264, Springer-Verlag, Berlin. Heidelberg.

Spurrier EC, Jackobs JA (1 955). Some Effects of an Anionic Sodium Sulfonate Type Surfactant upon Plant Growth. Contribution from the Department of Agronomy. Illinois Agr. Exp. Sta., Urbana.

U.S. Salinity Laboratory Staff. (1954). Diagnosis and Improvement of Saline and Alkali Soils. Agri. Handbook. No:60, USDA.

Walkley A, Black IA (1934). An examination of degtjareff method for determining soil organic matter and a proposed modifi cation of the chromic acid titration method. Soil Sci. $37: 29-37$

Yang $X$ (2008). Effects of a Nonionic Surfactant on Plant Growth and Physiology. Graduate Faculty of Auburn University Degree of Doctor of Philosophy Auburn, Alabama.

YIlmaz G, Dane F (2013). Phytotoxic effects of herbicide attribut and surfactant biopower on the root, stem, and leaf anatomy of Triticum aestivum 'Pehlivan'. Turkish Journal of Botany. 37:886-893. 